Pacific Journal of Mathematics

WFOWW-NVARLANT SETS 


\section{ON FLOW-INVARIANT SETS}

\section{G. S. LADDE AND V. LAKShMIKANTHAM}

\section{By employing Lyapunov-like functions and the theory of differential inequalities some sufficient conditions are given for flow-invariant and conditionally flow-invariant sets.}

1. In a recent paper Redheffer [6] has generalized a remarkable theorem of Bony [1] and has discussed its relation to a similar result of Brezis [2]. Results of general nature are also given by Ladde and Leela [4] which characterize various kinds of flow-invariant sets from a different point of view. In the present paper, we give theorems of very general character which offer sufficient conditions for flowinvariant sets in terms of Lyapunov-like functions and differential inequalities. These results include as special cases the theorems of Bony [1], Brezis [2], and Redheffer [6].

2. Let $E$ be a domain in real Euclidean space $R^{n}$ and $F \subset E$ be a closed set. For any set $A$, let $A^{0}, \partial A$ denote the interior, boundary of $A$ respectively. As usual, $d(x, A)$ denotes the distance of a point $x$ from the set $A$. We consider the differential system

$$
x^{\prime}=f(t, x), \quad x\left(t_{0}\right)=x_{0}, \quad t_{0} \in R^{+},
$$

where $f \in C\left[R^{+} \times E, R^{n}\right], R^{+}$being the half real line.

The set $F$ is flow-invariant for $f$ if

$$
x_{0} \in F \text { implies } x\left(t, t_{0}, x_{0}\right) \in F \text { for } t_{0} \leqq t<T
$$

where $\left[t_{0}, T\right)$ is the interval of existence of the solution $x\left(t, t_{0}, x_{0}\right)$ of (1).

Let $V \in C^{1}\left[R^{+} \times E, R^{+}\right]$and $y \in F$. Let, for each $t, S_{k}$ be the closed region around a fixed $x$ generated by $V(t, x-z) \leqq k$, that is, $S_{k}=[z: V(t, x-z) \leqq k]$. Suppose that $F \cap S_{k}^{0}=\varnothing$ and $y \in \partial S_{k}$. Then the vector $\gamma(t, y)=V_{x}(t, x-y)$ is said to be normal to $F$ at $y$ for each $t$.

The function $V(t, x-y)$ is said to be positive definite with respect to the set $F$, if $w(t, x)=\inf _{y \in F} V(t, x-y)$ is positive definite with respect to $f$.

Let $g \in C\left[R^{+} \times R^{+}, R\right], g(t, 0) \equiv 0$ and the only solution of

$$
u^{\prime}=g(t, u), \quad u\left(t_{1}\right)=0,
$$

on $t_{1} \leqq t<t_{1}+\varepsilon$ is identically zero, where $\varepsilon>0$ is some number, for every $t_{1} \in R^{+}$. Then we shall say that $g$ is a uniqueness function. 
We shall now prove the following result which offers sufficient conditions for a closed set $F$ to be flow-invariant relative to $f$.

THEOREM 1. Let the following assumptions hold:

(i) for $(t, x, y) \in R^{+} \times E \times F$,

$$
\begin{aligned}
V^{\prime}(t, x-y) & \equiv V_{t}(t, x-y)+V_{x}(t, x-y) \cdot[f(t, x)-f(t, y)] \\
& \leqq g(t, V(t, x-y)) ;
\end{aligned}
$$

(ii) $\gamma(t, y) \cdot f(t, y) \leqq 0$ whenever the vector $\gamma(t, y)$ is normal to $F$ at $y$ for each $t$;

(iii) $V(t, x-y)$ is positive definite with respect to the set $F$ and $g$ is a uniqueness function. Then the closed set $F$ is flow-invariant for $f$.

Proof. If the theorem is false, there exists a $t_{1}>t_{0}$ such that $x\left(t_{0}\right) \in F$ but $x(t) \notin F$ for $t_{1}<t<t_{2}$ for some $t_{2}$, on which $x(t)$ exists. Set $\varepsilon=t_{2}-t_{1}$. Thus we have $d[x(t), F]>0$ for $t_{1}<t<t_{2}$ and $d\left[x\left(t_{1}\right), F\right]=0$. Define $m(t)=w(t, x(t))$ for $t_{1} \leqq t<t_{2}$ and observe that $m\left(t_{1}\right)=0$ by (iii). For a fixed $t$ in $t_{1}<t<t_{2}$, let $x=x(t)$. It follows, by the definition of $w(t, x)$ and the fact that $F$ is closed, that there exists a $y_{0} \in F$ such that

$$
m(t)=V\left(t, x-y_{0}\right) .
$$

Consider the closed region $S_{k}=[z: V(t, x-z) \leqq k=m(t)]$. It is easily verified that $F \cap S_{k}^{0}=\varnothing$. This shows that by definition that the vector $\gamma\left(t, y_{0}\right)=V_{x}\left(t, x-y_{0}\right)$ is normal to $F$ at $y_{0}$. For small $h \geqq 0$ and for any $y \in F$, we have

$$
m(t+h)=w(t+h, x(t+h)) \leqq V(t+h, x(t+h)-y) .
$$

Hence

$$
m(t+h)-m(t) \leqq V\left(t+h, x(t+h)-y_{0}\right)-V\left(t, x(t)-y_{0}\right),
$$

which yields

$$
D^{+} m(t) \leqq V_{t}\left(t, x(t)-y_{0}\right)+V_{x}\left(t, x(t)-y_{0}\right) \cdot f(t, x(t)) .
$$

Consequently, using the assumptions (i) and (ii), we get

$$
D^{+} m(t) \leqq V^{\prime}\left(t, x(t)-y_{0}\right) \leqq g(t, m(t)), \quad t_{1}<t<t_{2} .
$$

By Theorem 1.4.1 in [5], we then obtain

$$
m(t) \leqq r\left(t, t_{1}, m\left(t_{1}\right)\right), \quad t_{1} \leqq t<t_{2},
$$

where $r\left(t, t_{1}, u_{0}\right)$ is the maximal solution of 


$$
u^{\prime}=g(t, u), \quad u\left(t_{1}\right)=u_{0} .
$$

Since $m\left(t_{1}\right)=0$, the hypothesis (iii) implies that

$$
m(t) \equiv 0 \quad \text { for } \quad t_{1} \leqq t<t_{2},
$$

which shows that $x(t) \in F$ for $t_{1}<t<t_{2}$. This contradiction proves the theorem.

The special case $V(t, x)=\|x\|^{2}$ and $\mathrm{g}(t, u)=\rho(u)$, where $\rho$ is a uniqueness function of Theorem 1 includes the important result of Bony [1] as generalized by Redheffer in [6].

For an example of $f$ which does not satisfy either a Lipschitz or a monotonicity condition but for which there does exist a Lyapunov function satisfying the uniqueness hypothesis of Theorem 1, see [3, p. 137].

3. In this section we shall generalize Theorem 1 a little further. Let $H \subset E$ be an open set such that $F \subset H$. Then the set $H$ is said to be conditionally flow-invariant for $f$ with respect to the set $F$, if

$x_{0} \in F$ implies $x\left(t, t_{0}, x_{0}\right) \in H$ for $t_{0} \leqq t<T$,

where $\left[t_{0}, T\right)$ is the interval of existence of $x\left(t, t_{0}, x_{0}\right)$ of (1). See [5] for the notion of conditionally invariant sets and their stability properties. We then have

THEOREM 2. Let the assumptions (i) and (ii) of Theorem 1 hold. Suppose further that

(a) $w(t, x)=\inf _{y \in F} V(t, x-y), \quad a \in C\left[R^{+}, R\right], \quad w(t, x) \geqq a(t), \quad$ if $x \in \partial H$ and $w(t, x)<a(t)$, if $x \in \partial F$;

(b) any solution $u\left(t, t_{1}, u_{0}\right)$ of $u^{\prime}=g(t, u), u\left(t_{1}\right)=u_{0}$, satisfies $u\left(t, t_{1}, u_{0}\right)<a(t)$, for $t_{1} \leqq t<t_{1}+\varepsilon$ where $\varepsilon>0$ is some number, provided $u_{0}<a\left(t_{1}\right)$ for every $t_{1} \in R^{+}$. Then the set $H$ is conditionally flow-invariant for $f$ with respect to the set $F$.

Proof. The proof is almost the same as that of Theorem 1. We shall only indicate the required changes.

Suppose that the theorem is false. Then there exists a $t^{*}>t_{0}$ such that $x_{0} \in F, x(t)=x\left(t, t_{0}, x_{0}\right) \in H$ for $t_{0} \leqq t<t^{*}$ and $x\left(t^{*}\right) \in \partial H$. This implies that there is a $t_{1}, t_{0} \leqq t_{1}<t^{*}$ such that $x\left(t_{1}\right) \in \partial F$ and $x(t) \in H \backslash F$ for $t_{1}<t<t^{*}$. By (a), we then have

$$
w\left(t^{*}, x\left(t^{*}\right)\right) \geqq a\left(t^{*}\right) \text { and } w\left(t_{1}, x\left(t_{1}\right)\right)>a\left(t_{1}\right) .
$$

Defining $m(t)=w(t, x(t))$, we proceed as in the proof of Theorem 1 till we arrive at the differential inequality (3). We now choose $u_{0}=$ $a\left(t_{1}\right)$ so that by Theorem 1.4.1 in [5], we get, as before, 


$$
m(t) \leqq r\left(t, t_{1}, a\left(t_{1}\right)\right), \quad t_{1} \leqq t<t^{*} .
$$

By the continuity of the functions involved, the assumption (b) and the relations (4), we arrive at the contradiction

$$
a\left(t^{*}\right) \leqq m\left(t^{*}\right) \leqq r\left(t^{*}, t_{1}, a\left(t_{1}\right)\right)<a\left(t^{*}\right) .
$$

Hence the proof is complete.

Notice that Theorem 2 enlarges the class of useful Lyapunovlike functions $V$ and offers more flexibility. To see this we give the following application.

THEOREM 3. Suppose that the following conditions hold:

(i ) $F \subset R^{n}$ is a closed set, $V \in C^{1}\left[R^{+} \times S(F, \rho) \backslash F, R\right]$ and $V^{\prime}(t, x-y) \leqq g(t, V(t, x-y))$ for $(t, x, y) \in R^{+} \times S(F, \rho) \backslash F \times F$;

(ii) $w(t, x)=\inf _{y \in F} V(t, x-y), \quad b \in C\left[R^{+} \times(0, \rho], \quad(-1, \infty)\right]$, $b(t, d(x, F)) \leqq w(t, x)$ for $(t, x) \in R^{+} \times S(F, \rho) \backslash F$, and $w(t, x) \rightarrow-1$ as $d(x, F) \rightarrow 0$ uniformity in $t$

(iii) $\gamma(t, y) \cdot f(t, y) \leqq 0$ whenever the vector $\gamma(t, y)$ is normal to $F$ at $y$ for each $t$;

(iv) $g \in C\left[R^{+} \times R, R\right]$ and any solution $u\left(t, t_{1}, u_{0}\right)$ of

$$
u^{\prime}=g(t, u), \quad u\left(t_{1}\right)=u_{0},
$$

satisfies $u\left(t, t_{1}, u_{0}\right)<b(t, \eta), t_{1} \leqq t<t_{1}+\varepsilon$, $\varepsilon$ is some positive number, provided $u_{0}<b\left(t_{1}, \eta\right)$ for every $t_{1} \in R^{+}$and a fixed $\eta \in(0, \rho]$. Then the set $S(F, \eta)$ is conditionally flow-invariant for $f$ with respect to $F$.

Proof. Since $w(t, x) \rightarrow-1$ as $d(x, F) \rightarrow 0$ uniformly in $t$,

$$
w(t, x)<b(t, \eta)
$$

for each $t \in R^{+}$, whenever $x \in \partial F$. Setting

$$
E=S(F, \rho) \backslash F, \quad H=S(F, \eta), \quad a(t)=b(t, \eta),
$$

we see that all the hypotheses of Theorem 2 are verified. Hence the conclusion follows.

If hypothesis (iv) holds for every $\eta \in(0, \rho]$, instead of a fixed $\eta$, Theorem 3 shows that $F$ is flow-invariant for $f$, because $\lim _{\eta \rightarrow 0} S(F, \eta)=F$.

4. We can formulate Theorem 1 in such a way as to include the result of Brezis [2] as generalized by Redheffer in [6].

THEOREM 4. Assume that all the hypotheses of Theorem 1 are satisfied except that the assumption (ii) is replaced by 
(ii*)

$$
\liminf _{h \rightarrow 0^{+}} \frac{1}{h} w(t, y+h f(t, y))=0 \quad \text { for each } y \in F \text {. }
$$

Then the conclusion of Theorem 1 remains valid. Provided that $w(t, x)$ possesses the property

$$
w\left(t, x_{1}\right)-w\left(t, x_{2}\right) \leqq V\left(t, x_{1}-x_{2}\right) .
$$

The condition (ii*) is needed only at each $y \in F$ that has a normal in the sense defined earlier. One can show that the hypothesis (ii*) together with (5) imply the assumption (ii) of Theorem 1. Indeed, let $\gamma(t, y)$ be normal to $F$ at $y$ for each $t$ and let $S_{k}$ be the closed region around a fixed $x$ generated by $V(t, x-z) \leqq k$ so that $\gamma(t, y)=$ $V_{x}(t, x-y)$. Since $S_{k}^{0} \cap F=\varnothing$, we have

$$
V(t, x-y)=w(t, x) .
$$

In view of the condition (5), this implies, for small $h>0$,

$$
V(t, x-y) \leqq V(t, x-y-h f(t, y))+w(t, y+h f(t, y)) .
$$

Hence

$$
0 \leqq V(t, x-y-h f(t, y))-V(t, x-y)+\varepsilon(h),
$$

where $\varepsilon(h)=w(t, y+h f(t, y))$. By (iv*), we see that

$$
\liminf _{h \rightarrow 0^{+}} \frac{\varepsilon(h)}{h}=0 \text {. }
$$

Consequently, the inequality (6) assures

$$
0 \leqq-V_{x}(t, x-y) \circ f(t, y)
$$

which is condition (iv) of Theorem 1.

We could have, following the proof of Theorem 1, directly proved Theorem 4. The proof crucially depends on the inequality (5). This we leave to the reader.

As before, the choice $V(t, x)=\|x\|$ or $\|x\|^{2}$ and $g(t, u)=\rho(u)$ where $\rho$ is a uniqueness function includes the result of Brezis [2] as given in [6]. Unfortunately, the restrictive condition (5) seems to be unavoidable which makes Theorem 4 less flexible compared to Theorem 1.

It is possible to formulate results analogous to Theorems 2 and 3 in the spirit of Theorem 4. This we do not undertake to avoid monotony. 


\section{REFERENCES}

1. Jean-Michel Bony, Principe du Maximum, inégalité Harnack et unicité du probléme de Cauchy pour les opérateurs elliptiques dégénéres, Ann. Inst. Fourier, Grenoble, 19 (1967), 277-304.

2. Hains Brezis, On a characterization of flow-invariant sets, Comm. Pure Appl. Math., 223 (1970), 261-263.

3. G. E. Ladas and V. Lakshmikantham, Differential Equations in Abstract Spaces, Academic Press, New York, 1972.

4. G. S. Ladde and S. G. Leela, Analysis of invariant sets, Annali de Matematica Pura ed Applicata, Series IV, XCIV (1972), 283-289.

6. R. M. Redheffer, The theorems of Bony and Brezis on flow-invariant sets, Amer. Math. Monthly, 79 (1972), 740-747.

5. V. Lakshmikantham and S. G. Leela, Differential and Integral Inequalities: Theory and Applications, Vol. I, Academic Press, New York, 1969.

Received December 21, 1972.

UNIVERSITY OF RHODE ISLAND 


\section{PACIFIC JOURNAL OF MATHEMATICS}

\section{EDITORS}

RICHARD ARENS (Managing Editor)

University of California

Los Angeles, California 90024

R. A. BeAumont

University of Washington

Seattle, Washington 98105
J. DugundJI*

Department of Mathematics

University of Southern California

Los Angeles, California 90007

D. Gilbarg and J. Milgram

Stanford University

Stanford, California 94305

\section{ASSOCIATE EDITORS}

E. F. BECKENBACH

B. H. NEUMANN

F. WOLF

K. YoSHIDA

\section{SUPPORTING INSTITUTIONS}

UNIVERSITY OF BRITISH COLUMBIA
CALIFORNIA INSTITUTE OF TECHNOLOGY
UNIVERSITY OF CALIFORNIA
MONTANA STATE UNIVERSITY
UNIVERSITY OF NEVADA
NEW MEXICO STATE UNIVERSITY
OREGON STATE UNIVERSITY
UNIVERSITY OF OREGON
OSAKA UNIVERSITY

UNIVERSITY OF BRITISH COLUMBIA CALIFORNIA INSTITUTE OF TECHNOLOGY UNIVERSITY OF CALIFORNIA MONTANA STATE UNIVERSITY NEW MEXICO STATE UNIVERSITY UNIVERSITY OF OREGON OSAKA UNIVERSITY
UNIVERSITY OF SOUTHERN CALIFORNIA STANFORD UNIVERSITY UNIVERSITY OF TOKYO UNIVERSITY OF UTAH WASHINGTON STATE UNIVERSITY UNIVERSITY OF WASHINGTON AMERICAN MATHEMATICAL SOCIETY NAVAL WEAPONS CENTER

* C. R. DePrima California Institute of Technology, Pasadena, CA 91109, will replace J. Dugundji until August 1974. 


\section{Pacific Journal of Mathematics}

\section{Vol. 51, No. $1 \quad$ November, 1974}

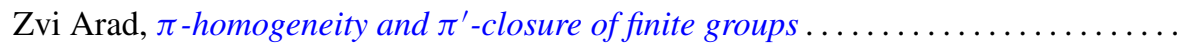

Ivan Baggs, A connected Hausdorff space which is not contained in a maximal

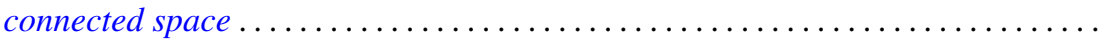

Eric Bedford, The Dirichlet problem for some overdetermined systems on the unit ball in $C^{n}$

R. H. Bing, Woodrow Wilson Bledsoe and R. Daniel Mauldin, Sets generated by

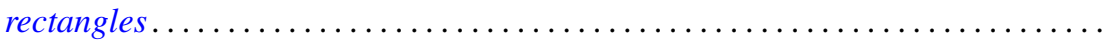

Carlo Cecchini and Alessandro Figà-Talamanca, Projections of uniqueness for

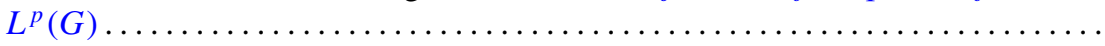

Gokulananda Das and Ram N. Mohapatra, The non absolute Nörlund summability of Fourier series .

Frank Rimi DeMeyer, On separable polynomials over a commutative ring ........ Richard Detmer, Sets which are tame in arcs in $E^{3} \ldots \ldots \ldots \ldots \ldots \ldots \ldots \ldots$

William Erb Dietrich, Ideals in convolution algebras on Abelian groups ..........

Bryce L. Elkins, A Galois theory for linear topological rings .................

William Alan Feldman, A characterization of the topology of compact convergence on $C(X)$.

Hillel Halkin Gershenson, A problem in compact Lie groups and framed cobordism

Samuel R. Gordon, Associators in simple algebras.

Marvin J. Greenberg, Strictly local solutions of Diophantine equations

Jon Craig Helton, Product integrals and inverses in normed rings . . . . . . . . . . . .

Domingo Antonio Herrero, Inner functions under uniform topology . . .

Jerry Alan Johnson, Lipschitz spaces .

Marvin Stanford Keener, Oscillatory solutions and multi-point boundary value

functions for certain nth-order linear ordinary differential equations.

John Cronan Kieffer, A simple proof of the Moy-Perez generalization of the

Shannon-McMillan theorem .......................

Joong Ho Kim, Power invariant rings

Gangaram S. Ladde and V. Lakshmikantham, On flow-invariant sets .

Roger T. Lewis, Oscillation and nonoscillation criteria for some self-adjoint even

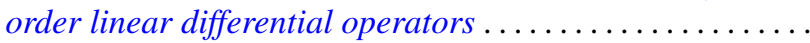

Jürg Thomas Marti, On the existence of support points of solid convex sets ..

John Rowlay Martin, Determining knot types from diagrams of knots . .

James Jerome Metzger, Local ideals in a topological algebra of entire functions

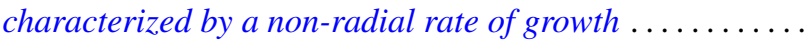

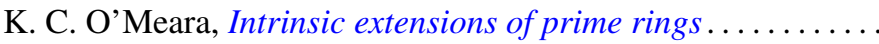

Stanley Poreda, A note on the continuity of best polynomial approximations ..

Robert John Sacker, Asymptotic approach to periodic orbits and local prolongations

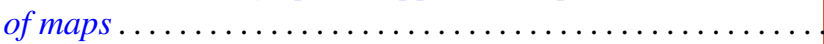

Eric Peter Smith, The Garabedian function of an arbitrary compact set . .

Arne Stray, Pointwise bounded approximation by functions satisfying a side condition

John St. Clair Werth, Jr., Maximal pure subgroups of torsion complete abelian

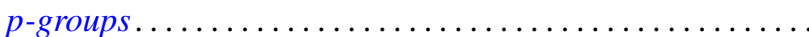

